\title{
Genetics of male infertility and related genes within Y chromosome
}

\author{
Tutku Melis Aygün ${ }^{1} *$
}

\begin{abstract}
Objective: The infertility is a reproductive health problem that affects nearly $7 \%$ of all couples in the human population. It has been estimated that nearly $50 \%$ of infertility cases are due to genetic defects. Male infertility may be contributory to $30-40 \%$ of infertile couples. Male infertility focuses on genetic factors impairing spermatogenesis and structural abnormalities such as $\mathrm{Y}$ chromosome microdeletions. The $\mathrm{Y}$ chromosome microdeletions are the most frequent genetic cause of male infertility. In this review article, we will focus on the structural abnormality and related gene functions on infertility.
\end{abstract}

Key words: AZF regions, male infertility, spermatogenetic failure, Y chromosome microdeletions

\section{Introduction}

Infertility is defined as the inability to conceive an offspring after a year of regular unprotected intercourse [1]. Nearly $15 \%$ of couples are affected with infertility, in which male factor infertility accounts for approximately $50 \%$ with genetic abnormalities such as structural abnormalities [2]. Genetic factors contribute to male infertility by influencing hormonal balance, spermatogenesis, and sperm quality. Male infertility screening is carried out by using semen analysis according to the standard criteria of the World Health Organization (WHO) [3].

In structural abnormalities, microdeletions of the $Y$ chromosome is considered to be a major cause of male infertility for azoospermic males [4]. Mostly the male infertility is a de novo event of genetic origin that originates during the normal process of spermatogenesis. Azoospermia is referred

to as the absence of spermatozoa in the ejaculate of a man. More than 4000 genes are mentioned to be involved in human spermatogenesis [5,6,7].

Recognition of Azoospermia Factor (AZF) region on the long arm of the $\mathrm{Y}$ chromosome $(\mathrm{Yq})$ is the second most common genetic cause of spermatogenic failure [8]. Molecular screening of $\mathrm{Y}$ chromosome microdeletions explain some related region that determine azoospermia factors like $\mathrm{AZFa}, \mathrm{AZFb}, \mathrm{AZFc}$ region which are responsible for regulating the spermatogenesis $[9,10]$.
In this review article, I present a brief overview of the AZFc subregion as microdeletions in this region that is a genetically risk factor for spermatogenic failure, also to understand the genetic problem of the AZFc subregion of the human Y chromosome [11,12].

\section{Structure and organization of y chromosome}

$\mathrm{Y}$ chromosome is the smallest chromosome that consists of $2-3 \%$ of the haploid genome and contains between 70 and 200 genes in their structure [13]. Cytogenetic observations are based on chromosome banding studies that are allowed different $\mathrm{Y}$ regions to be identified, the pseudoautosomal portion, PAR1 and PAR2, the euchromatic and heterochromatic regions.

Several phenotypes have been associated with the nonrecombining portion of the $\mathrm{Y}$ chromosome [14]. For obvious reasons, most of these are male-specific and make the $\mathrm{Y}$ a specialised chromosome during human evolution. The most characterising features of this chromosome remain its implication in human sex determination and in male germ cell development and maintenance [15,16].

Some of the important genes, also regions (Azoospermia Factor - AZF) on the human Y-chromosome have been discovered and then characterized [17]. These genes have been covered in this review. Important features such as cytogenetic location, function, and mutational deficiencies associated with some of the male-related genes are shown below in Table 1. 
Table 1. Male-Related Functional Genes (Azoospermia / Infertility)

\begin{tabular}{l|cllc|}
\hline GENE & LOCATION & \multicolumn{1}{c}{ LONG NAME } & FUNCTION & X HOMOLOGS \\
USP9Y & Yq: 5C & Ubiquitin-specific Protease & Azoospermia & + \\
\cline { 2 - 5 } DBY & Yq: 5C & DEAD box, Y & Infertility & + \\
UTY & Yq: 5C & Ubiquitous TRY motif, Y & Infertility & + \\
TB4Y & Yq: 5D & Thymosin 4, Y isoform & Infertility & + \\
EIF1AY & Yq: 5Q & Translation initiation factor 1A, Y & Infertility & + \\
CDY & Yq: 5L, 6F & Chromodomain, Y & Infertility & - \\
RBMY & Yp + q & RNA-binding motif, Y & Infertility & + \\
PRY & Y: 4A, 6E & Putative tyrosine phosphatase protein-related Y & Infertility & + \\
DAZ & Yq: 6F & Deleted in azoospermia &
\end{tabular}

Table 2. AZF Regions and Their Functions within the Y Chromosome

\begin{tabular}{c|c|} 
LOCUS & FUNCTIONS \\
AZF - A & Deletion of AZFa associated with lack of germ cells and Sertoli Cell Only Syndrome. \\
AZF - B & Deletion of AZFb associated with spermatogenesis arrest. \\
AZF - C & Deletion of AZFc associated with the failure of the maturation process of germ cells. \\
\hline
\end{tabular}

\section{Functional genes on three azf regions}

The azoospermia factor (AZF) region on the $\mathrm{Y}$ chromosome consists of genes required for spermatogenesis. The AZFa harbours some single-copy genes which are involved in spermatogenesis that have $\mathrm{X}$ homologs [18,19]. The overlapping $\mathrm{AZFb}$ and $\mathrm{AZFc}$ regions are jointly termed as $\mathrm{AZF} 2$. In the $\mathrm{AZFb}$ region, the eukaryotic translation initiation factor EIF1AY and RBMY genes have been mapped in man. EIF1A protein is involved in stabilizing the binding of the initiator methioninebearing-tRNA to $40 \mathrm{~S}$ ribosomal subunits.

The AZFc region harbours five genes: DAZ, BPY2, PRY. The candidate gene of AZFc is known as deleted in azoospermia gene, which is studied with interest because it is involved in germ cell development and most frequently deleted genes leading to azoospermia [20]. Also, AZF regions and their functions are shown in summarize, in Table 2 .

\section{Azf-a locus its genes and functions}

The AZFa encodes only single-copy genes. It is constituted by single-copy, ubiquitously expressed genes with $\mathrm{X}$ homologs that escape inactivation. genes have been mapped to AZFa.

*USP9Y: USP9Y is a single copy gene that is located in the AZFa region. USP9Y enzyme belongs to the peptidase C19 family and has a role in sperm cell production and development in mammals.

Besides, its role in spermatogenesis, studies have discovered that a nine-residue peptide derived from USP9Y represents a minor histocompatibility antigen involved in graft rejection.

*DBY: AZFa microdeletion is a result of non-homologous end joining (NHEJ) between two nearly identical repeats. The general view is the deletion of one gene is, this. DBY plays a key role in the spermatogenic process which is essential for cell cycle progression from $\mathrm{G} 1$ to $\mathrm{S}$ phase.
*UTY: In human, the six mRNA transcripts of UTY gene translate into the enzyme histone demethylase UTY that contains tetra-trico-peptide repeats and are thought to be involved in protein-protein interactions. The UTY protein being a minor histocompatibility antigen could induce rejection of male stem cell grafts. Suppression of recombination between the homologous genes UTY and Xchromosomal UTX, results in a point mutation in mRNA transcripts of these genes, whereas the reading frames. UTY has essential for prostate differentiation and that disruption of this network predisposes males to prostate cancer.

*TB4Y: TB4Y is expressed in various tissues that encodes a novel human leukocyte antigen HLA-A*3303-restricted, minor histocompatibility antigen and is a key activator of natural killer cell cytotoxicity. The involvement of TBY4 in testicular functions is unknown.

\section{Azf-b locus its genes and functions}

$\mathrm{AZFb}$ microdeletions cause spermatogenesis arrest at the spermatocyte stage, loss of mature sperm and milder azoospermia. The AZFb region has a complex structure that prone to NHEJ. The AZFb microdeletions remove multiple copies of testis-specific CDY, RBMY and PRY genes [21].

*CDY: This gene aids in regulation of gene expression and encodes a histone acetyltransferase. Deletion of this gene associated with azoospermia and severe oligozoospermia.

* RBMY: It is one of the most important genes of the $\mathrm{AZFb}$ region within the $\mathrm{Y}$ chromosome. Deletion of this gene leads to a decrease in sperm count in semen. RBMY must have diverse functional roles during different stages of spermatogenesis. Indeed analysis of the human testicular RBMY bound transcriptome have led to identification of 20 target genes some of which are testis-specific and have diverse cellular functions and is proposed to regulate alternative splicing during the spermatogenesis. 
*PRY: It is a testis-specific gene that encodes a protein similar to protein tyrosine phosphatase. When PRY levels are increased in sperm which can lead the abnormal semen parameters, suggesting a link between its expression and defective spermatogenesis.

\section{Azf-c locus its genes and functions}

$\mathrm{AZFa}$ and $\mathrm{AZFb}$ regions are essential in initiating spermatogenesis, the $\mathrm{AZFc}$ region is essential to complete the process of spermatogenesis [22,23]. The AZFc is the most commonly deleted region of the AZF locus in infertile men. There are no single-copy sequences in the AZFc. The AZFc region includes 12 genes and transcription units, each present in a variable number of copies making a total of 32 copies. Amongst the various transcriptional units, only active copies of four protein-coding gene families map to the AZFc interval. These include the PRY2, BPY2, DAZ and CDY1 [24,25].

*PRY2: The expression of PRY in germ cells is heterogeneous, with the protein being detected only in a few sperm and spermatids. Furthermore, PRY levels are increased in ejaculated sperm obtained from males with abnormal semen parameters, suggesting a link between its expression and defective spermatogenesis [26]. The PRY genes are thought to be involved in the regulation of apoptosis implicated in the removal of abnormal sperm. Deletions that include the PRY1 and PRY2 genes have also been reported to cause meiotic arrest.

*BPY2: It is expressed specifically in testis and its protein product is involved in male germ cell development. Three nearly identical copies of this gene exist on $\mathrm{Y}$ chromosome BPY2A, BPY2B and BPY2C. BPY2 is localized in the nuclei of spermatocytes, round spermatids and spermatogonia. The BPY2 gene encodes for a small positively charged protein which is thought to be involved in cytoskeletal regulation in spermatogenesis [27]. Due to its small size and high charge, it is thought that BPY proteins may functionally interact with DNA in a manner that resembles chromatin-associated proteins such as histones and high mobility group proteins which are known to play a role in the regulation of processes such as transcription, replication, recombination and DNA repair.

*DAZ: This is the first candidate gene to be isolated from the AZFc locus and was originally identified as a frequently deleted gene on the $\mathrm{Y}$ chromosome of infertile males. AZFc region contained palindromic duplications of DAZ as two clusters of four genes, DAZ1,2,3,4. The four DAZ copies are expressed in spermatogonia, encoding an RNAbinding protein important for spermatogenesis and these genes are expressed in all stages of germ cell development. Using human embryonic stem cells, it is shown that DAZ family genes function in germ cell formation. Therefore, all DAZ family genes are regarded as critical for germ cell development.

*CDY1: The human Y chromosome has two identical copies (CDY1A and CDY1B) of this gene within the AZFc region. This gene aids in regulation of gene expression, chromatin remodelling and encodes a histone acetyltransferase. This protein has been reported to concentrate in the round spermatid nucleus, where histone hyperacetylation occurs and causes the replacement of histones by the sperm-specific DNA packaging proteins.

\section{A genetic disorder related to $y$ chromosome abnormality}

\section{*Azoospermia}

The reproductive disorder of male known as azoospermia is characterized by the absence of sperm in ejaculate affecting approximately $20 \%$ of male fertility situations, in general. A variety of causes responsible for azoospermia which is due to abnormal chromosomes or structural abnormality. Disease-like varicocele is associated with the AZFa region of the $\mathrm{Y}$ chromosome. EIF1A protein results in azoospermia when deleted. Some studies have been investigated that deletion of DAZ1/DAZ2 but not DAZ3/DAZ4 is associated with spermatogenic failure [28,29].

\section{Male infertility and $y$ chromosome microdeletion}

Deletion of genetic material in the region of $\mathrm{Y}$ chromosome (AZF) results in male infertility. Some studies have been reported that the natural transmission of deletions which involves the USP9Y gene suggests that the absence of the USP9Y gene product does not have spermfertilizing ability. Thus, it is not critical for spermiogenesis. Deletion in DAZ1/DAZ2 gene copies, which is difficult to detect due to multicopy and will result in spermatogenetic failure [30].

Missing genes within the $\mathrm{Y}$ chromosome result in microdeletions. Y chromosome microdeletions are recently diagnosed by isolated DNA from peripheral blood (leukocytes) and then, mixing it with some of about hundreds of known genetic markers for sequence-tagged sites (STS) on the Y chromosome, then using PCR amplification -also FISH techniques (if it's possible)- and gel electrophoresis to test whether the DNA sequence corresponding to the selected markers is present in the DNA.

\section{Conclusion}

The advantages of next-generation sequencing and some of the new perspectives have enabled researchers to identify a number of novel genes. The Y chromosomal genes have been explored to associated with several male fertilityspecific traits in human.

Conflict of Interest: The authors declare no potential conflicts of interest with respect to the research, authorship, and/or publication of this article.

Author's Contributions: TMA; Research the literature, Collection of the Data, Preperation of review. TMA; Revision of the article.

\section{References}

1. Polani PE. Experiments on chiasmata and nondisjunction in mice. Hum Genet Suppl. 1981;2:145-146. 
2. Sinclair AH, Berta P, Palmer MS, et al. A gene from the human sexdetermining region encodes a protein with homology to a conserved DNA-binding motif. Nature. 1990;346:240-244.

3. Lahn BT, Page D. Functional coherence of the human Y chromosome. Science. 1997;278:675-680.

4. Tiepolo L, Zuffardi O. Localization of factors controlling spermatogenesis in the nonfluorescent portion of the human $\mathrm{Y}$ chromosome long arm. Hum Genet. 1976;34:119-124.

5. Jacobs PA, Ross A. Structural abnormalities of the $\mathrm{Y}$ chromosome in man. Nature. 1966;210:352-354

6. Buhler EM. A synopsis of the human Y chromosome. Hum Genet. 1980;55:145-175.

7. Vergnaud G, Page DC, Simmler MC, et al. A deletion map of the human $\mathrm{Y}$ chromosome based on DNA hybridization. Am J Hum Genet. 1986;38:109-124. [PMC free article]

8. Vollrath D, Foote S, Hilton A, et al. The human Y chromosome: a 43-interval map based on naturally occuring deletions. Science. 1992;258:52-59.

9. Foote S, Vollrath D, Hilton A, et al. The human Y chromosome: overlapping DNA clones spanning the euchromatic region. Science. 1992;258:60-66.

10. Graves JAM. The origin and function of the mammalian Y chromosome and Y-borne genes - an evolving understanding. Bioessays. 1995; 17:311-320.

11. Bull JJ. Evolution of sex determining mechanism. Menlo Park: Benjamin Cummings.

12. Arnemann AJ, Epplen J, Cooke H, et al. A human Y chromosomal DNA sequence expressed in testicular tissue. Nucl Acids Res. 1987;15:8713-8724. [PMC free article]

13. Page DC, Mosher R, Simpson, et al. The sex-determining region of the human $\mathrm{Y}$ chromosome encodes a finger protein. Cell. 1987;51:1091-1104.

14. Fisher EMC, Beer-Romero P, Brown LG, et al. Homologous ribosomal protein genes on the human $\mathrm{X}$ and $\mathrm{Y}$ chromosome: escape from $\mathrm{X}$ inactivation and possible implication for Turner Syndrome. Cell. 1990;63:1205-1218.

15. Hassold TJ, Sherman SL, Pettay D, Page DC, Jacobs PA. XY chromosome nondisjunction in man is associated with diminished recombination in the pseudoautosomal region. Am J Hum Genet. 1991;49:253-260. [PMC free article]

16. Ross MT, Grafham DV, Coffey AJ, Scherer S, McLay K, et al. The DNA sequence of the human X chromosome. Nature. 2005;434:325337. [PMC free article]

17. Ellison JW, Wardak Z, Young MF, GehronRobey P, Laig-Webster $\mathrm{M}$, Chiong W. PHOG, a candidate gene for involvement in the short stature of turner syndrome. Hum Mol Genet. 1997;6:1341-1347.
18. Rao E, Weiss B, Fukami M, Rump A, Niesler B, Mertz A, Muroya K, Binder G, Kirsch S, Winkelmann M, Nordsiek G, Heinrich U, Breuning MH, Ranke MB, Rosenthal A, Ogata T, Rappold GA. Pseudoautosomal deletions encompassing a novel homeobox gene cause growth failure in idiopathic short stature and turner syndrome. Nat Genet. 1997;16:54-63.

19. Lencz T, Morgan TV, Athanasiou M, Dain B, Reed CR, et al Converging evidence for a pseudoautosomal cytokine receptor gene locus in schizophrenia. Mol Psychiatry. 2007;12:572-580.

20. Flaquer A, Jamra RA, Etterer K, Di'az GO, Rivas F, et al. A new susceptibility locus for bipolar affective disorder in PAR1 on Xp22.3/Yp11.3. Am J Med Genet. 2010;153B:1110-1114.

21. Mangs Helena A, Morris BJ. The human pseudoautosomal region (PAR): origin, function and future. Curr Genomics. 2007;8:129-136. [PMC free article]

22. Charchar FJ, Svartman M, El-Mogharbel N, Ventura M, Kirby P, Matarazzo MR, Ciccodicola A, Rocchi M, D’Esposito M, Graves JA. Complex events in the evolution of the human pseudoautosomal region 2 (PAR2) Genome Res. 2003;13:281-286. [PMC free article]

23. Lopes AM, Ross N, Close J, Dagnall A, Amorim A, Crow TJ Inactivation status of PCDH11X: sexual dimorphisms in gene expression levels in brain. Hum Genet. 2006;119:267-275

24. Veerappa AM, Padakannaya P, Ramachandra NB. Copy number variation-based polymorphism in a new pseudoautosomal region 3 (PAR3) of a human X-chromosome-transposed region (XTR) in the Y chromosome. Funct Integr Genomics. 2013;13:285-293.

25. Manz E, Alkan M, Bühler E, Schmidtke J. Arrangement of DYZ1 and DYZ2 repeats on the human Y-chromosome: a case with presence of DYZ1 and absence of DYZ2. Mol Cell Probes. 1992;6:257-259.

26. Cotter PD, Norton ME. Y chromosome heterochromatin variation detected at prenatal diagnosis. Prenat Diagn. 2005;25:1062-1063.

27. Skaletsky H, Kuroda-Kawaguchi T, Minx PJ, Cordum HS, Hillier L, Brown LG, Repping S, Pyntikova T, Ali J, Bieri T, et al. The malespecific region of the human $\mathrm{Y}$ chromosome is a mosaic of discrete sequence classes. Nature. 2003;423:825-837.

28. Maan AA, Eales J, Akbarov A, Rowland J, Xu X, Jobling MA, Charchar FJ, Tomaszewski M. The Y chromosome: a blueprint for men's health? Eur J Hum Genet. 2017;25:1181-1188. [PMC free article]

29. Meyfour A, Pooyan P, Pahlavan S, Rezaei-Tavirani M, Gourabi H, Baharvand H, Salekdeh GH. Chromosome-centric human proteome project allies with developmental biology: a case study of the role of Y chromosome genes in organ development. J Prot Res. 2017; 10.1021/acs.jproteome.7b00446. [PubMed]

30. Rengaraj D, Kwon WS, Pang MG. Bioinformatics annotation of human Y chromosome-encoded protein pathways and interactions. J Prot Res. 2015;14:3503-3518.

Copyright (C) 2019 The Author(s); This is an open-access article distributed under the terms of the Creative Commons Attribution License (http://creativecommons.org/licenses/by/4.0), (CC BY NC) which permits unrestricted use, distribution, and reproduction in any medium, provided the original work is properly cited. International journal of Medical Science and Discovery. 